\title{
Inflammatory bowel disease: clinical aspects and treatments
}

This article was published in the following Dove Press journal:

Journal of Inflammation Research

23 June 2014

Number of times this article has been viewed

\author{
Marc Fakhoury' \\ Rebecca Negrulj² \\ Armin Mooranian ${ }^{2}$ \\ Hani Al-Salami ${ }^{2}$ \\ 'Biomedical Technology and Cell \\ Therapy Research Laboratory, \\ Department of Biomedical \\ Engineering and Artificial Cells and \\ Organs Research Center, Faculty of \\ Medicine, McGill University, Montreal, \\ QC, Canada; ${ }^{2}$ Biotechnology and Drug \\ Development Research Laboratory, \\ Curtin Health Innovation Research \\ Institute, Biosciences Research \\ Precinct, School of Pharmacy, Curtin \\ University, Perth, WA, Australia
}

\begin{abstract}
Inflammatory bowel disease (IBD) is defined as a chronic intestinal inflammation that results from host-microbial interactions in a genetically susceptible individual. IBDs are a group of autoimmune diseases that are characterized by inflammation of both the small and large intestine, in which elements of the digestive system are attacked by the body's own immune system. This inflammatory condition encompasses two major forms, known as Crohn's disease and ulcerative colitis. Patients affected by these diseases experience abdominal symptoms, including diarrhea, abdominal pain, bloody stools, and vomiting. Moreover, defects in intestinal epithelial barrier function have been observed in a number of patients affected by IBD. In this review, we first describe the types and symptoms of IBD and investigate the role that the epithelial barrier plays in the pathophysiology of IBD as well as the major cytokines involved. We then discuss steps used to diagnose this disease and the treatment options available, and finally provide an overview of the recent research that aims to develop new therapies for such chronic disorders.
\end{abstract}

Keywords: inflammatory bowel disease, Crohn's disease, ulcerative colitis, cytokines

\section{Introduction}

The inflammatory bowel diseases (IBDs) primarily include Crohn's disease and ulcerative colitis. Crohn's disease is an IBD that causes inflammation anywhere along the lining of the digestive tract, while ulcerative colitis causes long-lasting inflammation in some part of the digestive tract (mainly the colon). The exact etiology of IBD is not well known. There are several factors that have been postulated to have an effect on the development of this group of diseases, which include but are not limited to bacterial contamination, a change in the immune system, and genetic variations. For instance, a mutation in the NOD2 gene is associated with an increase susceptibility to IBD via production of proinflammatory cytokines. ${ }^{1}$ While genetic predisposition plays a key role in immune-mediated diseases, the major influence appears to be due to environmental factors. ${ }^{2}$ Indeed, current research suggests that autoimmune diseases are most prevalent in highly industrialized nations but rare in less developed countries. ${ }^{3}$ Moreover, studies have shown that increased consumption of milk protein, animal protein, and polyunsaturated fatty acids can increase the risk for IBD, ${ }^{4}$ and that consumption of tobacco increases the risk of Crohn's disease. ${ }^{5}$

The major subtypes of IBD, including Crohn's disease and ulcerative colitis, have a high prevalence rate in the world, with North America noting the highest frequency of people suffering with Crohn's disease. In addition, statistics show that an estimated 129,000 people live with the disease in Canada. Although the onset of the disease usually occurs
Correspondence: Marc Fakhoury

I Ste Catherine 1506, H2VIZ8,

Montreal, QC, Canada

Tel +I 5I47I0 7060

Email marc.fakhoury@mail.mcgill.ca 
during adulthood, children are increasingly being diagnosed with IBD. Treating IBD often involves use of medications that can diminish the symptoms and decrease the inflammation in the colon lining. A group of anti-inflammatory drugs including 5-aminosalicylic acid is commonly used to treat IBD. ${ }^{6}$ Other drugs such as infliximab are also indicated in patients who have failed conventional therapy and are hospitalized with severe IBD. Infliximab is a chimeric monoclonal antibody against tumor necrosis factor alpha (TNF- $\alpha$ ), a cytokine involved in intestinal inflammation. Several other immunomodulatory drugs, such as thalidomide, can also be used to treat a patient with severe IBD. Formerly used as a sedative and hypnotic, this synthetic drug has been shown to significantly reduce the inflammation associated with IBD. ${ }^{7}$ However, under certain circumstances, when medical therapy fails, surgery may be considered. This operation is known as colectomy and involves removal of the large intestine. While ulcerative colitis is cured upon removal of the colon, Crohn's disease unfortunately can still recur after surgery.

While medication is commonly used to treat IBD, most pharmaceutical compounds have side effects such as headache, diarrhea, and nausea, which can reduce patient compliance and result in worsening of the condition. Therefore, appropriate delivery systems must be developed in order to overcome the limitations and issues associated with the currently available treatments for IBD. Artificial cell microencapsulation is a promising tool in scientific research that allows for targeted delivery of pharmaceutical compounds in a time-dependent fashion. ${ }^{7}$ Current research aims at developing such a platform in order to deliver anti-inflammatory drugs to the areas of the gastrointestinal tract most affected by IBD.

\section{Types and symptoms of IBD}

Although Crohn's disease and ulcerative colitis share similar characteristics, they differ in terms of the location and nature of the inflammatory changes. The distinction between these two diseases is that in Crohn's disease inflammation can affect any part of the gastrointestinal tract, while ulcerative colitis is characterized by inflammation localized to the large intestine. The prevalence of Crohn's disease is relatively high in highly industrialized countries. Its incidence is five in 100,000 people and its prevalence is estimated to be $30-50$ of 100,000 people in western countries. ${ }^{8}$ At the microscopic level, Crohn's disease affects the entire bowel wall, while ulcerative colitis is restricted to the epithelial lining of the gut. Since the two diseases share similar symptoms, the diagnosis of one form of IBD over the other is often very difficult. As previously mentioned, medical treatment of IBD is strongly dependent on the use of immunosuppressive drugs and anti-inflammatory compounds. ${ }^{9}$ Although immunosuppressive therapies such as azathioprine, mercaptopurine, and methotrexate are currently available, achieving remission of IBD in patients remains a clinical challenge. ${ }^{10}$ This class of therapeutics is very efficient in reducing the extent of inflammation, but it presents a wide range of side effects. For instance, administration of such pharmaceutical compounds can cause fluid retention, insomnia, weight gain, drowsiness, hypertension, constipation, and vomiting. Therefore, in the ongoing research for additional therapeutics, several studies have focused on the development of new formulations to treat IBD with minimal side effects, improved patient compliance, and therefore better clinical outcomes.

Symptoms tend to vary depending on the type of IBD. A comparison of the key features in Crohn's disease and ulcerative colitis is shown in Table 1. Patients affected by ulcerative colitis tend to experience pain in the lower left part of the abdomen as well as diarrhea. As a result, they may experience weight loss and blood on rectal examination. In contrast, patients with Crohn's disease experience pain in the lower right abdomen, and bleeding from the rectum is less frequent than in ulcerative colitis. The most common complication of Crohn's disease is blockage of the intestine due to swelling, which results in thickening of the bowel wall. Moreover, people affected by this disease often encounter problems related to malnutrition or the presence of nutritional deficiencies, as a result of poor absorption. Several studies have found an increased risk of death in people affected by Crohn's disease. Analyses of colorectal and small bowel cancer studies have found that people with Crohn's disease also suffered with comorbidities such as colorectal cancer, cardiovascular disease, and respiratory disease. ${ }^{11,12}$ Similarly, there have been several studies of the mortality associated with ulcerative colitis. However, no significant difference in

Table I Comparison of key features in Crohn's disease and ulcerative colitis

\begin{tabular}{lll}
\hline Key features & Crohn's disease & Ulcerative colitis \\
\hline $\begin{array}{l}\text { Location } \\
\text { Upper parts of GIT }\end{array}$ & Rarely & Never \\
Distal lleum & Very common & Never \\
Colon & Common & Always \\
Rectum & Rarely & Never \\
Signs and symptoms & Pain in the lower & Pain in the lower left \\
& right abdomen, & abdomen, diarrhea, \\
& swelling, thickening & weight loss, rectal \\
& of the bowel wall & bleeding \\
\hline
\end{tabular}

Abbreviation: GIT, gastrointestinal tract. 
mortality risk was reported with ulcerative colitis. Indeed, it was shown that people with ulcerative colitis have the same mortality risk as the general population. ${ }^{13,14}$

\section{Intestinal barrier in IBD}

Understanding the properties and characteristics of the gastrointestinal tract can aid in the identification of the biomolecular mechanisms involved in IBD, and can foster new ideas for the development of therapies for such chronic disorders. A variety of defense mechanisms are aimed at minimizing infections caused by IBD, and include physical barriers such as tightly adherent epithelial cells, antimicrobial peptides secreted by intestinal epithelial cells, and complex mucosal innate and adaptive immune arms aimed at eliminating invasive infections. ${ }^{15}$ The gastrointestinal tract consists of four separate layers that reflect specialization in functional anatomy, ie, the mucosa, submucosa, muscularis externa, and adventitia. ${ }^{16}$ The mucosa is the inner layer of the gastrointestinal tract and plays a very significant role in the digestion of food. It forms a barrier between the internal organs and the lumen of the gastrointestinal tract. This layer mainly consists of epithelial cells that are connected by tight junctions and play an important role in allowing the transport of nutrients across the epithelium, while preventing the passage of molecules that might be harmful to the host. ${ }^{17}$ These epithelial linings also contain goblet cells and endocrine cells. ${ }^{18}$ The sole function of goblet cells is to secrete mucin, which forms mucus when dissolved in water. Endocrine cells, commonly found in the epithelial wall, secrete a type of hormone that plays a crucial role in the regulation of digestive processes. External microorganisms that are able to breach the epithelial wall have unrestricted access to the circulation, which is one of the main causes of gastrointestinal disease. Indeed, murine and human studies have demonstrated that IBDs, such as Crohn's disease, are characterized by a defect in the epithelial barrier and altered mucus production, leading to an increase in intestinal permeability and toxins adherence in the intestinal cells. ${ }^{15,19}$

As illustrated in Figure 1, Crohn's disease is characterized by a defect in the integrity of the epithelial barrier, resulting in translocation of microbial antigens and other external agents. ${ }^{20}$ Several studies have demonstrated increased adherent bacteria in patients with Crohn's disease. ${ }^{15}$ Exposure of the mucosal immune system to external luminal contents will significantly increase the production of proinflammatory cytokines and favor a differentiation of T-cells to T-helper (Th)1-type effector cells, which triggers the release of proinflammatory cytokines.

\section{Role of cytokines in IBD}

Th cells are a subclass of lymphocytes that play a key role in mediating the immune response. They are involved in activating other immune cells and in determining the specificity of antibodies secreted by B-cells. ${ }^{21,22}$

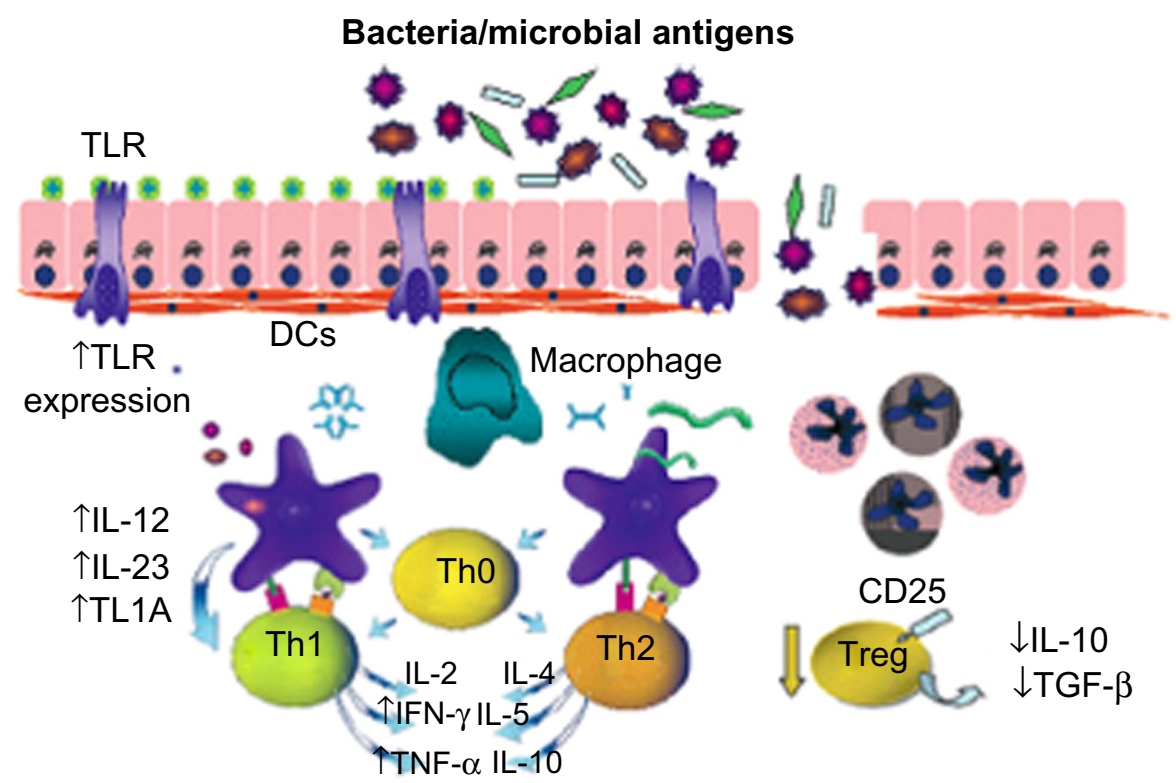

Figure I Triggering of immune response in Crohn's disease. The main molecules involved are TGF- $\beta$, Tregs, TLR, DCs, Th cells, and TLIA.

Note: Reprinted from Cobrin GM, Abreu MT. Defects in mucosal immunity leading to Crohn's disease. Immunol Rev. 2005;206:277-295.20 Copyright @ 2005, John Wiley and Sons.

Abbreviations: DCs, dendritic cells; TGF- $\beta$, transforming growth factor beta; Tregs, regulatory T-cells; TLR, Toll-like receptors; Th, T-helper; TLIA, TNF-like ligand IA; IL, interleukin; TNF- $\alpha$, tumor necrosis factor alpha; IFN- $\gamma$, interferon gamma. 


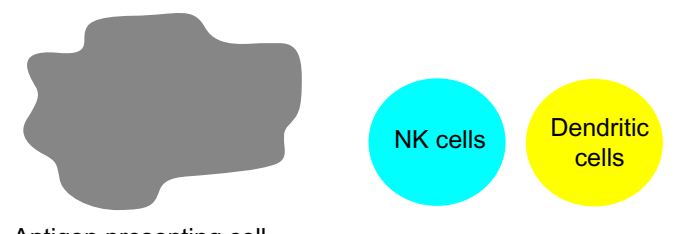

Antigen presenting cell

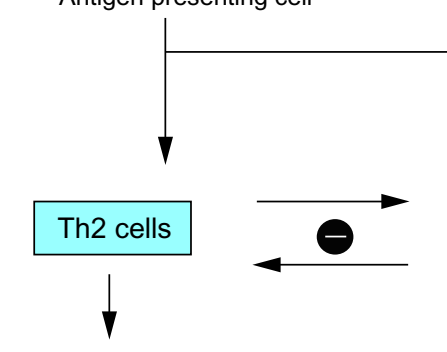

Humoral immunity

IL-4, IL-6, IL-10

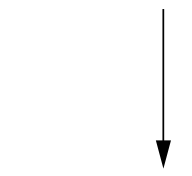

Chronic inflammation is suppressed

Figure 2 Factors determining T-lymphocyte differentiation in inflammatory bowel disease.

Abbreviations: Th, T-helper; IL, interleukin; TNF- $\alpha$, tumor necrosis factor alpha; IFN- $\gamma$, interferon gamma; NK, natural killer.

Upon proliferation, a Th cell differentiates into Th1 cells, Th2 cells, or other Th lineages. As shown in Figure 2, Th1 cells mediate the production of proinflammatory cytokines, such as interferon gamma (IFN- $\gamma$ ), TNF- $\alpha$, and interleukin (IL)-2, which are part of cell-mediated immunity. In contrast, Th2 cells lead to production of anti-inflammatory cytokines, including IL-4, IL-5, IL-6, and IL-10, which constitute the humoral immune response. There is a mutual interaction between Th1 and Th2 lymphocytes; Th1 cytokines drive Th1 cell production and inhibit Th2 cells. Conversely, Th2 cytokines drives Th 2 cell production and inhibit Th1 cells. In a normal situation, there is a balance between the amounts of Th2 and Th1 cells. ${ }^{11}$ The development of immune-mediated disorders like Crohn's disease is strongly related to a polarized type 1 immune response causing chronic inflammation of the gut. ${ }^{22}$

Administration of anti-inflammatory drugs protects the individual from Crohn's disease by attenuating the Th1 response and enhancing Th2-mediated activity. This immune modulation causes a switch of the immune response from a Th1-mediated to a Th2-mediated activity, thus significantly reducing the extent of bowel inflammation. ${ }^{23,24}$
TNF- $\alpha$ is a proinflammatory cytokine that plays a major role in the inflammation caused by IBD. Levels of TNF- $\alpha$ are significantly increased in response to intestinal inflammation. Indeed, clinical studies have demonstrated that serum TNF- $\alpha$ levels are elevated in patients with IBD. ${ }^{25}$ Elevated TNF- $\alpha$ levels can be confirmed in a patient by viewing both histologically normal mucosa and inflamed mucosa. An increase in TNF- $\alpha$ induces cell proliferation and differentiation, and leads to upregulation of adhesion molecules on endothelial cells. ${ }^{26}$ TNF- $\alpha$ is also involved in apoptosis via recruitment and autoproteolytic activation of caspases. Therefore, the aim of the current research is to design an anti-TNF- $\alpha$ therapy that can dampen the inflammation related to IBD in patients.

\section{Diagnosis of IBD}

Several techniques and medical tests are available to aid the physician in the diagnosis of IBD. Such a technique is available for Crohn's disease, and utilizes capsule endoscopy to diagnose a patient effectively. Since capsule endoscopy requires a clean colon prior to use, the patient should take an appropriate drinking formulation that has a good safety profile. The capsule, which is the size of a pill, can take pictures of the inner layer of the gastrointestinal tract when orally ingested. These endoscopic images can localize small erosions and ulcerations that may be evident along the gastrointestinal tract and help physicians identify the location of inflammation. ${ }^{27}$ An alternative to endoscopy is radiology tests that can aid in the diagnosis of the disease. For example, a barium follow-through procedure is a useful medical imaging technique for Crohn's disease when only the small intestine is involved. ${ }^{28}$ In this technique, the patient drinks a solution containing barium sulfate that appears white on X-ray and highlights the internal lining of the bowel. Another diagnostic tool for IBD involves testing of blood samples from patients. Laboratory blood tests may show elevated sedimentation rates and white cell counts, both of which are associated with intestinal inflammation. Complete blood counts from patients with IBD may reveal anemia caused by vitamin B12 deficiency and autoimmune hemolysis. ${ }^{29}$ Moreover, increasing amounts and levels of serological markers may be useful in the diagnosis of IBD and also for differentiation between Crohn's disease and ulcerative colitis. ${ }^{30,31}$

$\mathrm{X}$-ray computed tomography and magnetic resonance imaging scans are also commonly used to look for intraabdominal complications of IBD, such as small bowel obstruction, abscesses, or fistulae. ${ }^{32}$ Computed tomography 
is a technique that utilizes multidetector scanners with high spatial and temporal resolution in order to permit visualization of the small bowel wall, mucosa, and lumen. ${ }^{33}$ It can delineate the extent and severity of inflammation of the bowel wall, and can also detect submucosal fat deposition, sacculations, and fibrofatty proliferation. The presence of intramural fat indicates past or chronic inflammation, while sacculations result from the chronic inflammatory process, leading to fibrosis and asymmetric shortening of the mesenteric border of the wall. ${ }^{34}$ Magnetic resonance imaging has undergone the same technical advances as seen with computed tomography. Its spatial and temporal resolution of images allows evaluation of bowel wall contrast enhancement, wall thickening, and edema, which is useful for assessment of IBD activity. ${ }^{33}$

Biopsies of the colon can be taken to confirm the diagnosis. This technique is very effective in diagnosing the disease and in differentiating the type of inflammation. Certain features of the pathology seem to be characteristic of the inflammation associated with Crohn's disease. A transmural pattern of inflammation is often seen in this disease, meaning that the inflammation may span the entire depth of the intestinal wall. Under the microscope, biopsy of the affected colon may show mucosal damage, characterized by focal infiltration of leukocytes into the epithelium. ${ }^{7}$ Granulomas, ie, aggregates of immune cells known as macrophages, are also found (Figure 3) and are most specific for Crohn's disease..$^{35}$

The pathology in ulcerative colitis typically involves hemorrhage or inflammatory cells in the lamina propria

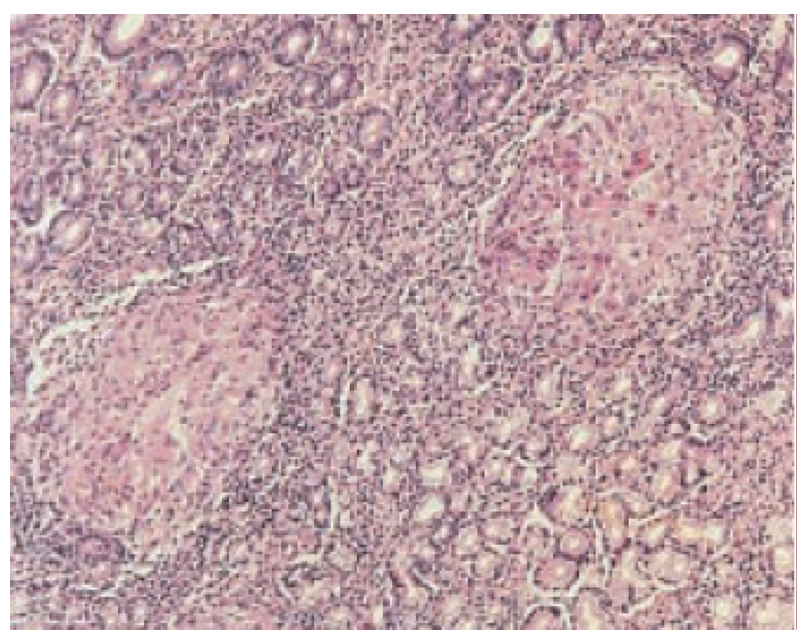

Figure 3 Granulomas in Crohn's disease. Hematoxylin and eosin staining on the stomach shows gastric mucosal biopsy containing two characteristic granulomas $(10 \times)$. and distortion of crypt architecture. The latter is the result of crypt abscess, during which the epithelium of the crypt breaks down and polymorphonuclear cells aggregate in the lumen. ${ }^{35}$

Other differences between Crohn's disease and ulcerative colitis can be observed on histology, as shown in Table 2. For instance, significant thickening of the mucosa and to a lesser extent in the submucosa can be observed in patients with active ulcerative colitis. However, these structures appear to be quite normal in active Crohn's disease. ${ }^{36}$

\section{Major treatments and limitations Medication used for IBD}

There is no known medical or surgical cure for IBD. Treatment of the disease involves use of anti-inflammatory drugs that can significantly reduce the symptoms of the disease and help maintain its remission. Medications used to treat the symptoms of IBD include anti-inflammatory drugs, such as 5-aminosalicylic acid, ${ }^{37}$ and immunomodulators, such as azathioprine, mercaptopurine, methotrexate, infliximab, adalimumab, certolizumab, and natalizumab. These compounds regulate the immune system by efficiently triggering a Th2-mediated response that dampens Th1-mediated inflammation. This results in production of anti-inflammatory cytokines such as IL-4, IL-5, IL-6, and IL-10 that inhibit production of proinflammatory cytokines. Oral delivery of such compounds has been shown to be successful against intestinal inflammation, ${ }^{8}$ but has several limitations when administered in high doses. These limitations are mainly due to the fact that most of the administered drug is delivered to nonspecific cells in the body, resulting in either infusion reactions or undesirable side effects.

\section{Monoclonal antibodies}

Anti-TNF- $\alpha$ antibodies are frequently used to treat IBD because they are able to efficiently reduce the amount of

Table 2 Histologic and endoscopic findings in Crohn's disease versus ulcerative colitis

\begin{tabular}{|c|c|c|}
\hline Key features & Crohn's disease & Ulcerative colitis \\
\hline $\begin{array}{l}\text { Histologic } \\
\text { findings }\end{array}$ & $\begin{array}{l}\text { Transmural } \\
\text { inflammation, } \\
\text { presence of } \\
\text { granulomas }\end{array}$ & $\begin{array}{l}\text { Mucosal and submucosal } \\
\text { inflammation, polymorphonuclear } \\
\text { cells aggregate }\end{array}$ \\
\hline $\begin{array}{l}\text { Endoscopic } \\
\text { findings }\end{array}$ & $\begin{array}{l}\text { Discontinuous } \\
\text { lesions, strictures, } \\
\text { linear ulcerations }\end{array}$ & $\begin{array}{l}\text { Continuous lesions, presence } \\
\text { of crypts, formation of residual } \\
\text { mucosal tissue }\end{array}$ \\
\hline
\end{tabular}


TNF- $\alpha$ in the body. Recent studies suggest that infliximab, a monoclonal antibody, is a potential treatment for Crohn's disease because it neutralizes TNF- $\alpha$ by preventing it from interacting with its receptor. ${ }^{38,39}$ The complementarities between the TNF- $\alpha$ molecule and the variable region of infliximab make this antibody a promising treatment for Crohn's disease and other autoimmune disorders. However, there are major limitations associated with infliximab in that patients can develop tuberculosis soon after the initiation of treatment, which is often due to TNF- $\alpha$ neutralization. ${ }^{40}$ Delayed hypersensitivity reactions are also frequently observed following administration of infliximab. Moreover, infliximab cannot be administered orally, since the digestive system would destroy it, and needs to be administered via an intravenous infusion at 6-8-week intervals. Other antibodies, such as adalimumab and certolizumab, have also shown significant positive results in the treatment of IBD. ${ }^{41}$

\section{Thalidomide}

Thalidomide was first manufactured by a German pharmaceutical company and was found to be an effective sedative and tranquilizer for insomnia, colds, and headaches. It was introduced onto the market in 1957 in several countries as an immunomodulatory agent to treat diseases such as multiple myeloma. However, it was withdrawn from the market in 1961 after it was found to be associated with severe birth defects when administered during pregnancy, ${ }^{42}$ but was then approved in July 1988 by the US Food and Drug Administration. The drug can now be administered to patients in the USA under strict guidelines. Thalidomide is involved in the pathophysiology of Crohn's disease since it suppresses all the major cytokines that participate in intestinal inflammation. Likewise, thalidomide destabilizes TNF- $\alpha$ messenger RNA, leading to a significant decrease in the amount of TNF- $\alpha$, a proinflammatory cytokine responsible for the inflammation of Crohn's disease. ${ }^{43}$ It also stimulates the production of cytotoxic T-cells, resulting in an increase in the number of T-lymphocytes. ${ }^{44}$ Although thalidomide is beneficial in dampening the production of proinflammatory cytokines, it has several limitations, including drowsiness, hypertension, skin rash, edema, and neutropenia. Appropriate drug delivery systems must be developed in order to successfully release thalidomide in the areas of the gastrointestinal tract most affected by the disease.

\section{Drug-loaded microcapsules}

Artificial cell microencapsulation is a promising tool in scientific research that allows the delivery of pharmaceutical compounds to specific tissues in the body in a timedependent manner. ${ }^{45}$ Artificial cell microencapsulation involves preparation of an artificial structure using different types of polymers and proteins. It can contain a variety of molecular structures, including DNA, drugs, enzymes, antibodies, bacteria cells, mammalian cells, and other microorganisms. ${ }^{46}$ Several publications suggest the use of alginate-polylysine-alginate (APA) microcapsules as an efficient platform for the delivery of pharmaceutical compounds. ${ }^{7,45}$ APA microcapsules are formed by ionic interactions between negatively charged alginate molecules and positively charged calcium ions. Preliminary data suggest that APA capsules remain intact in the low $\mathrm{pH}$ environment normally encountered in the stomach. ${ }^{47}$ In the small intestine, the capsule degrades at a slow rate and releases its content in a time-dependent manner. The in vivo biocompatibility of artificial microcapsules has been demonstrated, and they have shown no signs of clinical toxicity. ${ }^{48}$ A recent study has evaluated the potential of artificial cell microencapsulation of thalidomide in the remission of Crohn's disease using a well established model of 2,4,6-trinitrobenzene sulfonic acid-induced inflammation in mice. ${ }^{7}$ It was shown that this artificial structure could release the drug into the intestines and decrease the degree of intestinal inflammation by lowering the level of proinflammatory cytokines, while at the same time limiting the side effects associated with thalidomide.

\section{Conclusion}

Although there is no cure for IBD, we now have sufficient evidence that several pharmaceutical compounds are able to dampen the intestinal inflammation. This review provides an overview of the experimental studies done using monoclonal antibodies and anti-inflammatory drugs. Most of the results reported in the papers show that anti-inflammatory compounds can inhibit the proliferation of cytokines such as TNF- $\alpha$ and IFN- $\gamma$, but unfortunately have potential side effects, including vomiting, diarrhea, and nausea. Use of appropriate drug delivery systems such as artificial cell microencapsulation has shown promising results with regard to limiting these side effects as well as enhancing the inhibition of intestinal inflammation. However, many questions still remain. Existing studies are encouraging, but most are inconclusive. More research, both in animal models and in clinical trials, is necessary to validate the newer and potentially more effective treatment options for the eventual commercialization of new IBD therapies. The coming years will be crucial. The information obtained 
from ongoing and future clinical trials will help us better understand the pathophysiology of intestinal inflammation in IBD and may have a significant impact on treating patients with the disease.

\section{Author contributions}

Each author participated intellectually and practically in this work, and can take public responsibility for the content of this review. All authors read and approved the final manuscript.

\section{Disclosure}

The authors report no conflict of interest in this work.

\section{References}

1. Ogura Y, Bonen DK, Inohara N, et al. A frameshift mutation in NOD2 associated with susceptibility to Crohn's disease. Nature. 2001;411:603-606.

2. Ponder A, Long DM. A clinical review of recent findings in the epidemiology of inflammatory bowel disease. Clin Epidemiol. 2013;5: 237-247.

3. Weinstock JV, Summers R, Elliott DE. Helminths and harmony. Gut. 2004;53:7-9

4. Shoda R, Matsueda K, Yamato S, Umeda N. Epidemiologic analysis of Crohn disease in Japan: increased dietary intake of $n-6$ polyunsaturated fatty acids and animal protein relates to the increased incidence of Crohn disease in Japan. Am J Clin Nutr. 1996;64:741-745.

5. Hovde O, Moum B. Epidemiology and clinical course of Crohn's disease: results from observational studies. World J Gastroenterol. 2012;18:1723-1731

6. Sandborn WJ, Feagan BG, Lichtenstein GR. Medical management of mild to moderate Crohn's disease: evidence-based treatment algorithms for induction and maintenance of remission. Aliment Pharmacol Ther. 2007;26:987-1003.

7. Fakhoury M, Coussa-Charley M, Al-Salami H, Kahouli I, Prakash S. Use of artificial cell microcapsule containing thalidomide for treating TNBS-induced Crohn's disease in mice. Curr Drug Deliv. 2014;11: $146-153$

8. Cassinotti A, Ardizzone S, Porro GP. Adalimumab for the treatment of Crohn's disease. Biologics. 2008;2:763-777.

9. Ljung T, Karlén P, Schmidt D, et al. Infliximab in inflammatory bowel disease: clinical outcome in a population based cohort from Stockholm County. Gut. 2004;53:849-853.

10. Bauditz J, Wedel S, Lochs H. Thalidomide reduces tumour necrosis factor alpha and interleukin 12 production in patients with chronic active Crohn's disease. Gut. 2002;50:196-200.

11. Canavan C, Abrams KR, Mayberry J. Meta-analysis: colorectal and small bowel cancer risk in patients with Crohn's disease. Aliment Pharmacol Ther. 2006;23:1097-1104.

12. Jess T, Gamborg M, Matzen P, Munkholm P, Sørensen TI. Increased risk of intestinal cancer in Crohn's disease: a meta-analysis of population-based cohort studies. Am J Gastroenterol. 2005;100: 2724-2729.

13. Hutfless SM, Weng X, Liu L, Allison J, Herrinton LJ. Mortality by medication use among patients with inflammatory bowel disease. Gastroenterology. 2007;133:1779-1786.

14. Höie O, Schouten LJ, Wolters FL, et al; European Collaborative Study Group of Inflammatory Bowel Disease (EC-IBD). Ulcerative colitis: no rise in mortality in a European-wide population based cohort ten years after diagnosis. Gut. 2007;56:497-503.
15. Swidsinski A, Ladhoff A, Pernthaler A, et al. Mucosal flora in inflammatory bowel disease. Gastroenterology. 2002;122:44-54.

16. Sarriá R, Latorre R, Henroteaux M, et al. Morphometric study of the layers of the canine small intestine at five sampling sites. Vet $J$. 2012;192:498-502.

17. Hawiger J. Innate immunity and inflammation: a transcriptional paradigm. Immunol Res. 2001;23:99-109.

18. Moore WF, Bentley RC, Kim KR, Olatidoye B, Gray SR, Robboy SJ. Goblet-cell mucinous epithelium lining the endometrium and endocervix: evidence of metastasis from an appendiceal primary tumor through the use of cytokeratin-7 and -20 immunostains. Int J Gynecol Pathol. 1998;17:363-367.

19. Schreiber O, Petersson J, Waldén T, et al. iNOS-dependent increase in colonic mucus thickness in DSS-colitic rats. PLoS One. 2013;8:e71843.

20. Cobrin GM, Abreu MT. Defects in mucosal immunity leading to Crohn's disease. Immunol Rev. 2005;206:277-295.

21. Kidd P. Th1/Th2 balance: the hypothesis, its limitations, and implications for health and disease. Altern Med Rev. 2003;8:223-246.

22. Kugathasan S, Saubermann LJ, Smith L, et al. Mucosal T-cell immunoregulation varies in early and late inflammatory bowel disease. Gut. 2007;56:1696-1705

23. Fichtner FS, Fuss IJ, Preiss JC, Strober W, Kitani A. Treatment of murine Th1- and Th2-mediated inflammatory bowel disease with NF- $\mathrm{kB}$ decoy oligonucleotides. J Clin Invest. 2005;115:3057-3071.

24. Rutgeerts P, Geboes K. Understanding inflammatory bowel disease - the clinician's perspective. Eur J Surg. 2001;167:66-72.

25. Thomson A, Gupta M, Freeman H. Use of the tumor necrosis factor-blockers for Crohn's disease. World J Gastroenterol. 2012;18: $4823-4854$

26. Clauss M, Ryan J, Stern D. Modulation of endothelial cell hemostatic properties by TNF: insights into the role of endothelium in the host response to inflammatory stimuli. In: Beutler B, editor. Tumor Necrosis Factors: The Molecules and Their Emerging Role in Medicine. New York, NY, USA: Raven Press; 1992.

27. Tanaka S, Mitsui K, Shirakawa K, et al. Successful retrieval of video capsule endoscopy retained at ileal stenosis of Crohn's disease using doubleballoon endoscopy. J Gastroenterol Hepatol. 2006;21: 922-923.

28. Eliakim R, Suissa A, Yassin K, Katz D, Fischer D. Wireless capsule video endoscopy compared to barium follow-through and computerised tomography in patients with suspected Crohn's disease - final report. Dig Liver Dis. 2004;36:519-522.

29. Hruz P, Eckmann L. Innate immune defence: NOD2 and autophagy in the pathogenesis of Crohn's disease. Swiss Med Wkly. 2010;140: w13135.

30. Papp M, Altorjay I, Dotan N, et al. New serological markers for inflammatory bowel disease are associated with earlier age at onset, complicated disease behavior, risk for surgery, and NOD2/CARD15 genotype in a Hungarian IBD cohort. Am J Gastroenterol. 2008;103: 665-681.

31. Stein J, Hartmann F, Dignass AU. Diagnosis and management of iron deficiency anemia in patients with IBD. Nat Rev Gastroenterol Hepatol. 2010;7:599-610.

32. Zissin R, Hertz M, Osadchy A, Novis B, Gayer G. Computed tomographic findings of abdominal complications of Crohn's disease pictorial essay. Can Assoc Radiol J. 2005;56:25-35.

33. Vilela E, Torres H, Martins F, Ferrari M, Andrade M, Cunha A. Evaluation of inflammatory activity in Crohn's disease and ulcerative colitis. World J Gastroenterol. 2012;18:872-881.

34. Paulsen SR, Huprich JE, Hara AK. CT enterography: noninvasive evaluation of Crohn's disease and obscure gastrointestinal bleed. Radiol Clin North Am. 2007;45:303-315.

35. Geboes K. Histopathology of Crohn's disease and ulcerative colitis. In: Satsangi J, Sutherland LR. Inflammatory Bowel Diseases. 4th edition. New York, NY, USA: Churchill-Livingstone; 2003:255-276.

36. Ellrichmann M. Endoscopic ultrasound of the colon for the differentiation of Crohn's disease and ulcerative colitis in comparison with healthy controls. Aliment Pharmacol Ther. 2014;39:823-833. 
37. Burger D, Travis S. Conventional medical management of inflammatory bowel disease. Gastroenterology. 2011;140:1827-1837. e2.

38. Cohen RD. Efficacy and safety of repeated infliximab infusions for Crohn's disease: 1-year clinical experience. Inflamm Bowel Dis. 2001;7:S17-S22.

39. Eggert M, Seeck U, Semmler M, et al. An evaluation of anti-TNF-alphatherapy in patients with ankylosing spondylitis: imbalanced activation of NF kappa B subunits in lymphocytes and modulation of serum cortisol concentration. Rheumatol Int. 2007;27:841-846.

40. Keane J, Gershon S, Wise RP, et al. Tuberculosis associated with infliximab, a tumor necrosis factor alpha-neutralizing agent. $N$ Engl $J$ Med. 2001;345:1098-1104.

41. Lee TW, Fedorak RN. Tumor necrosis factor- $\alpha$ monoclonal antibodies in the treatment of inflammatory bowel disease: clinical practice pharmacology. Gastroenterol Clin North Am. 2010;39: 543-557.

42. Kuehn BM. Frances Kelsey honored for FDA legacy: award notes her work of thalidomide, clinical trials. JAMA. 2010;304:2109-2110.
43. Moreira AL, Sampaio EP, Zmuidzinas A, Frindt P, Smith KA, Kaplan G. Thalidomide exerts its inhibitory action on tumor necrosis factor alpha by enhancing mRNA degradation. $J$ Exp Med. 1993;177:1675-1680.

44. Zhu Y, Kortuem K, Stewart AK. Molecular mechanism of action of immune-modulatory drugs thalidomide, lenalidomide and pomalidomide in multiple myeloma. Leuk Lymphoma. 2013;54:683-687.

45. Metz T, Haque T, Chen H, Prakash S, Amre D, Das SK. Preparation and in vitro analysis of microcapsule thalidomide formulation for targeted suppression of TNF alpha. Drug Deliv. 2006;13:331-337.

46. Chang T. Artificial cells in immobilization biotechnology. Biomater Artif Cells Immobilization Biotechnol. 1992;20:1121-1143.

47. Jones ML, Chen H, Ouyang W, Metz T, Prakash S. Microencapsulated genetically engineered Lactobacillus plantarum 80 (pCBH1) for bile acid deconjugation and its implication in lowering cholesterol. J Biomed Biotechnol. 2004;2004:61-69.

48. Shen F, Mazumder MA, Burke NA, Stöver HD, Potter MA. Mechanically enhanced microcapsules for cellular gene therapy. J Biomed Mater Res B Appl Biomater. 2009;90:350-361.

\section{Publish your work in this journal}

The Journal of Inflammation Research is an international, peer-reviewed open-access journal that welcomes laboratory and clinical findings on the molecular basis, cell biology and pharmacology of inflammation including original research, reviews, symposium reports, hypothesis formation and commentaries on: acute/chronic inflammation; mediators of inflamma-

\section{Dovepress}

tion; cellular processes; molecular mechanisms; pharmacology and novel anti-inflammatory drugs; clinical conditions involving inflammation. The manuscript management system is completely online and includes a very quick and fair peer-review system. Visit http://www.dovepress.com/ testimonials.php to read real quotes from published authors. 